\title{
Desafios do trabalho docente: mudança ou repetição
}

\author{
Elisabeth Diefenthaeler Krahe \\ Programa de Pós-graduação em Educação \\ elzkrahe@terra.com.br \\ Liane Margarida Rockenbach Tarouco \\ Programa de Pós-graduação em Informática da Educação \\ liane@penta.ufrgs.br \\ Mary Lúcia Pedroso Konrath \\ Programa de Pós-graduação em Educação \\ mary@ cinted.ufrgs.br
}

Universidade Federal do Rio Grande do Sul

Brasil

\begin{abstract}
Resumo. A partir de uma conceituação teórica realizada com base nos autores TARDIF \& LESSARD, ALARCÃO e MORAN apresentam-se alguns resultados de pesquisas desenvolvidas por um grupo de pesquisadoras sobre o trabalho docente, expondo alguns desafios enfrentados no cotidiano destes profissionais a partir do uso das novas tecnologias de informação $e$ comunicação (NTIC). Pretende-se também falar sobre as estratégias pedagógicas que são planejadas e usadas por professores no uso destes recursos, analisando se estas práticas se diferenciam ou repetem o ensino tradicional através do uso de recursos tecnológicos mais antigos e conhecidos destes profissionais, tais como: quadro-negro, livros impressos, etc. $O$ artigo pretende levantar reflexões sobre como afinal está sendo o uso dos computadores e laboratório de informática nas escolas.
\end{abstract}

Palavras-chave: trabalho docente, NTIC, estratégias pedagógicas

\section{Introdução}

O que cada vez mais ouvimos entre os estudiosos e pesquisadores é que a mudança na educação é inevitável. Diante das mudanças da sociedade e da invenção de novas tecnologias de informação e comunicação, professores e alunos têm a clara sensação de que a aprendizagem deve ser encarada de outra forma, indo além da mera transmissão de conhecimentos.

Precisamos ter clareza das diferenças existentes entre ensino e educação, para que possamos buscar uma educação de qualidade. As novas tecnologias estão em foco e muitos têm expectativas que elas sejam a solução, contudo precisamos nos dar conta que elas quando bem empregadas podem mudar e qualificar as práticas pedagógicas, mas apenas tê-las na escola e usá-las de qualquer maneira não é garantia de melhoria deste processo.

Neste artigo será apresentado o que se entende pelo trabalho docente a partir de (TARDIF e LESSARD, 2005) e quais são alguns dos desafios enfrentados pelos professores no seu cotidiano frente aos seus instrumentos de trabalho, tais como os encontrados no uso das novas tecnologias de informação e comunicação. Neste sentido, o grupo apresentará alguns papéis de orinentador/mediador que podem fazer parte do trabalho do docente na perspectiva da mediação pedagógica. 
Serão exploradas também as estratégias pedagógicas que são planejadas e usadas por professores no uso destes recursos tecnológicos, analisando se estas práticas se diferenciam ou repetem o ensino tradicional.

Por fim, pretende-se apresentar algumas experiências de como estão sendo usados os computadores e laboratório de informática nas escolas.

\section{Trabalho docente}

O trabalho docente é permeado por teoria e ações práticas, produz resultados sobre o humano, requer reflexão teórica-prática permanente, aprofundamento e formação continuada. Sua complexidade envolve a interação com alunos e colegas, planejamento e gestão educacional do ensino, avaliação, transformações curriculares, etc... Neste sentido, conforme (TARDIF e LESSARD, 2005, p. 8) a docência é “...uma forma particular de trabalho sobre o humano, ou seja, uma atividade em que o trabalhador se dedica ao seu "objeto" de trabalho, que é justamente um outro ser humano, no mundo fundamental da interação humana".

Por isto ele é complexo e interativo e está em estado de tensão frente aos desafios impostos pela sociedade em que vivemos hoje, contraditória, complexa e que cada vez mais pressiona a escola e os professores para que transformem-se e adquiram novas competências, aprendendo e ensinando aos alunos como lidar com uma avalanche de informações e as mídias que nos afetam a todo instante.

O espaço para execução do trabalho docente é a escola, uma organização na qual vários outros sujeitos (diretor, funcionários, pais, comunidade, etc...) intervém/interagem uns com os outros. Desta forma, reafirma-se que um professor trabalha com e sobre os seres humanos, sofrendo influências das diversas esferas e coletividades humanas.

Esse profissional faz parte então de um dos processos mais importantes da vida, a Educação, que é segundo (MORAN et al., 2000, p. 12) “...além de ensinar, é ajudar a integrar ensino e vida, conhecimento e ética, reflexão e ação, a ter uma visão de totalidade. Educar é ajudar a integrar todas as dimensões da vida, a encontrar nosso caminho intelectual, emocional, profissional, que nos realize e que contribua para modificar a sociedade que temos".

Já o Ensino é entendido como um processo mais voltado à compreensão do mundo como ele é e porque ele é assim, segundo o mesmo autor, p. 12. no ensino "organiza-se uma série de atividades didáticas para ajudar os alunos a compreender áreas específicas do conhecimento (ciências, história, matemática)". Ele fala ainda que ensinar é “...um processo social (inserido em cada cultura, com suas normas, tradições e leis), mas também é um processo profundamente pessoal: cada um de nós desenvolve um estilo, seu caminho, dentro do que está previsto para a maioria.”.

Desta forma (MORAN et al., 2000, p. 14) diz que o ensino de qualidade envolve muitas variáveis e entre elas podemos citar:

- Organização inovadora, aberta, com um projeto pedagógico coerente, dinâmico, participativo e inovador

- Infra-estrutura adequada, atualizada, confortável

- Tecnologias acessíveis, disponíveis e adequadas

- Profissionais preparados intelectual, emocional, comunicacional e eticamente e com boa remuneração 
- Condições de trabalho adequadas para estes profissionais

- Tempo para os profissionais, pesquisarem e estudarem

Estas variáveis influenciam diretamente no Ensino e também na Educação e infelizmente a realidade no Brasil hoje ainda está muito distante do que foi apresentado. Desta forma, os professores são desafiados no seu cotidiano a trabalharem com os instrumentos e tecnologias que lhe estão disponíveis. Veja a partir de agora alguns desafios enfrentados pelos professores no uso das Novas Tecnologias de Informação e Comunicação.

\section{Desafios do cotidiano do trabalho docente frente as NTIC}

Cada professor tem um grande leque de possibilidades de organizar sua aula de forma que ela seja dinâmica, inovadora, principalmente a partir de propostas que utilizem as Novas Tecnologias de Informação e Comunicação de forma apropriada e contextualizada. (MORAN et al., 2000, p. 32) nos diz que "uma parte importante da aprendizagem acontece quando conseguimos integrar todas as tecnologias, as telemáticas, as audiovisuais, as textuais, as orais, musicais, lúdicas, corporais".

O desafio está em encontrar tempo para conhecer as novas tecnologias, ler sobre elas, atualizar-se e planejar o seu uso, prevendo com seus alunos objetivos, caminhos e atividades para desenvolver a pesquisa, organizando os momentos coletivos e individuais e a avaliando o processo de cada sujeito, diante de tanta pressão e sobrecarga que enfrentam os professores em seu trabalho cotidiano. Mais complicado ainda é conseguir fazer um trabalho integrado com outros professores, tornando a aprendizagem um processo global e interdisciplinar, assim como conseguir compartilhar experiências interessantes e prazerosas realizadas com seus alunos com outros colegas dentro da mesma instituição ou fora dela.

Nesse contexto é importante destacar o papel da aprendizagem dentro e fora da sala de aula, assim como o do professor nesta sociedade. Conforme (ALARCÃO, 2004, p. 27) a sala de aula é "...um espaço onde se procura e onde se produz conhecimento" e o professor tem como funções (ALARCÃ̃, 2004, p. 30) "criar, estruturar e dinamizar situações de aprendizagem e estimular a aprendizagem e auto-confiança nas capacidades individuais para aprender..." Esta autora afirma também que através de suas pesquisas verificou que (2004, p. 31) "a escola e os professores não estão preparados para o trabalho que hoje lhes é exigido em função de seus novos papéis". Entre estes novos papéis está um papel muito importante que diz respeito a função de mediação e orientação dos alunos na busca da produção de conhecimentos.

\section{Mediação pedagógica e o papel do professor como mediador/orientador}

A mediação pedagógica refere-se à relação do professor com seu objeto de trabalho, o aluno, na busca da aprendizagem como algo que precisa ser construído, a partir de uma reflexão crítica das experiências e do processo de trabalho do professor.

A partir deste viés o professor tem a função de ser facilitador, incentivador e mediador da aprendizagem de seus alunos. Segundo (PEREZ e CASTILLO,1999, p.10): “A mediação pedagógica busca abrir um caminho a novas relações do estudante: com os materiais, com o próprio contexto, consigo mesmo e com seu futuro". 
O professor nesta perspectiva de mediação pedagógica pode assumir o papel de orientador/mediador (MORAN et al., 2004, p. 30) que pode ser classificado como:

- Orientador/medi(ador intelectual

- Orientador/mediador emocional

- Orientador/mediador gerencial e comunicacional

- Orientador ético

O papel de orientador/mediador intelectual diz respeito ao perfil do professor que trabalha selecionando, informando e ajudando seus alunos a escolher informações de forma significativa, para que os mesmos possam re-elaborá-las, ressignificá-las e compreendê-las.

O papel de orientador/mediador emocional refere-se ao envolvimento motivacional que engloba entre outros aspectos: o estímulo e incentivo.

O Orientador/mediador gerencial e comunicacional é o papel responsável pela organização e direção do trabalho em grupos, atividades de pesquisa e avaliação.

$\mathrm{O}$ orientador ético diz respeito às relações éticas, relacionadas a valores humanos, culturais para o convívio individual e coletivo.

Desta forma, o mesmo autor sugere alguns princípios metodológicos norteadores para a prática pedagógica de professores:

- Integração de tecnologias, metodologias e atividades, aproximando as diversas mídias existentes.

- Variar a forma e as técnicas utilizadas em sala de aula e fora dela, improvisando e não deixando assim tudo previsível e monótono.

- Planejar e improvisar quando necessário, ajustando o planejado as circunstâncias da prática.

- Valorizar a comunicação virtual e os aspectos de presença e distância.

A partir da leitura de (MORAN et al, 2000) vemos as técnicas que se pode usar para favorecer a aprendizagem na perspectiva da mediação pedagógica, entre elas temos as estratégias convencionais e as das novas tecnologias.

Ele chama de estratégias convencionais: (2000, p.146) “...[...] aquelas que servem para dinamizar o processo de aprendizagem de seus alunos". Elas são caracterizadas por ele em grupos distintos, num primeiro grupo temos (p.147): “... [...] técnicas de apresentação simples, apresentação cruzada em duplas, complementação de frases, desenhos em grupo, deslocamentos físicos dos alunos e do professor, tempestade cerebral”. No segundo grupo, (p.147) “[...] dramatização, desempenho de papéis, jogos dramáticos, jogos de empresa, estudos de caso". No terceiro grupo, (p.148) “ [...] estágios, excursões, aulas práticas (didática, clínica), visita a obras, indústrias, empresas, presença em ambulatórios, escolas, consultórios, escritórios, no fórum, enfim, em locais próprios das atividades profissionais". Temos também as técnicas de dinâmicas de grupo, aulas expositivas, uso de recursos audiovisuais, leituras e por último a estratégia de ensino com pesquisa ou por meio de projetos.

As estratégias de novas tecnologias são (MORAN et al., 2000, p.146) “[...] aquelas que estão vinculadas ao uso do computador, à informática, à telemática e à educação a distância". Elas incluem diversos recursos e linguagens digitais que podem modificar o 
processo de educação através da interação entre os sujeito por intermédio das tecnologias.

Neste sentido, se retoma a importância de se pensar no uso das tecnologias de forma integrada, para tanto é necessário o planejamento do processo de aprendizagem assim como o estudo do que será trabalhado, para que se possam planejar também as técnicas que serão empregadas, objetivos e o que se pretende que seja realizado com cada grupo de alunos em sala de aula.

Estes princípios podem nortear professores a planejarem o uso das Novas Tecnologias de Informação e Comunicação, entre elas o computador e a Internet, através da elaboração de um planejamento que contenha estratégias pedagógicas e técnicas contextualizadas e condizentes, com o trabalho que está sendo realizado em sala de aula.

\section{Planejamento e estratégias pedagógicas}

O planejamento educacional diz respeito ao plano que orienta as decisões do professor, de sua concepção de educação, aprendizagem, da forma de planejar e no conhecimento que deve ser trabalhado.

Manata nos fala da importância do planejamento como:

[...] um pressuposto essencial para assegurar não somente o alcance dos
objetivos da prática docente, mas também para definir a competência do
professor na sua trajetória profissional, com base nos aspectos didáticos de
sua disciplina. A organização e o desenvolvimento planejados das atividades
didáticas -pedagógicas criam as condições necessárias para uma atuação
docente mais eficiente e eficaz no processo ensino-aprendizagem. Os planos
constituem o cenário sobre o qual vão ser delineadas as competências e as
habilidades a serem asseguradas aos alunos, no âmbito das diferentes
disciplinas. (MANATA, 2004, p. 07).

Através deste é preciso estabelecer objetivos educacionais do tema a ser tratado, as estratégias educacionais e atividades de avaliação, representando as responsabilidades do professor e seus objetivos de forma clara e mais completa possível. Manata confirma a importância das estratégias considerando que "o processo de planejamento visa promover a mudança nas estratégias docentes da prática pedagógica cotidiana" (2004, p. $8)$.

Faz parte dele também, conforme Gandin:

[...] Elaborar - decidir que tipo de sociedade e de homem se quer e que tipo de ação educacional é necessária para isso; verificar a que distância se está deste tipo de ação e até que ponto se está contribuindo para o resultado final que se pretende; propor uma série orgânica de ações para diminuir esta distancia e para contribuir mais para o resultado final estabelecido; executar agir em conformidade com o que foi proposto e avaliar - revisar sempre cada um desses momentos e cada uma das ações, bem como cada um dos documentos deles derivados (GANDIN, 1985, p.22).

O planejamento deve ser feito a partir de referências na busca de intencionalidades, percebendo que a ação pedagógica deve estar sustentada por pressupostos teóricos, os quais segundo Rodrigues (2002, p.17) "estabelecem as diretrizes do trabalho, definindo procedimentos e estratégias metodológicas. [... ] planejar é a constante busca de aliar o "para que" ao "como" [...]" 
A partir de leituras sobre planejamento, foi possível observar que o planejamento educacional segue uma orientação pedagógica e que há diferentes linhas que orientam as formas de organizar o planejamento. As estratégias pedagógicas fazem parte deste planejamento e podem seguir uma ou mais técnicas integradas.

As estratégias pedagógicas são os meios que o professor utiliza em sala de aula para facilitar o processo de ensino-aprendizagem, incluindo:

- as concepções educacionais que embasam as atividades propostas;

- a articulação de propostas e/ou atividades desencadeadoras de aprendizagens;

- a organização do ambiente físico;

- a utilização de recursos áudio-visuais,

- o planejamento de ações e

- o tipo e a forma como o material é utilizado.

Nesse contexto o professor precisa utilizar-se dos processos de reflexão e planejamento, num contínuo exercício. É importante que este ao planejar as estratégias pedagógicas, verifique sua estrutura institucional, tradições metodológicas, possibilidades reais dos meios e condições físicas disponíveis no seu ambiente de trabalho.

\section{Experiências de uso dos computadores e laboratórios nas escolas}

As mudanças tecnológicas têm provocado profundas transformações na realidade social, exigindo dos sujeitos o domínio das tecnologias e técnicas que são entendidas como um conjunto de ferramentas tecnológicas, que se refletem no processo educacional, confirmando a importância do uso dos computadores e das novas tecnologias digitais também na Educação. Com isso, precisamos estar atentos que o uso dessas ferramentas tecnológicas tão somente não é garantia de uma transformação efetiva e qualitativa nas práticas pedagógicas.

A seleção das tecnologias educacionais ou a incorporação delas na prática pedagógica é uma ação atrelada aos saberes docentes em torno de seus códigos e linguagens, de suas características e particularidades, de suas possibilidades e limitações. Dessa forma, os professores precisam conhecer as tecnologias educacionais para que possam adotá-la de forma efetiva e eficaz, incorporando-a com propriedade à sua práxis.

Incorporar a tecnologia na escola dentro dos pressupostos das teorias que solicitam, dos agentes comunicativos, interação e interatividade e construção de conhecimentos ajustada ao nível e a realidade de cada aluno, de modo a poder contribuir para o processo de aprendizagem coletiva e cooperativa - requer, no mínimo, tempo de estudo e desejo de aprender. Sem essas duas condições primeiras, as tecnologias até podem estar presentes na escola, porém não estarão inseridas em abordagem que as assumam como elementos mediadores da compreensão da realidade em que vivemos.

As novas tecnologias nos permitem a ampliar a nossa prática de sala de aula, mas é preciso planejar o uso das mesmas visando à aprendizagem dos alunos e não somente para servir como mais um suporte para transmissão de informações.

As experiências de uso dos computadores e laboratórios de informática nas escolas são bem diferenciadas, enquanto algumas não têm equipamentos, outras apenas poucas máquinas usadas sem muitos recursos, outras desfrutam de máquinas e softwares 
sofisticados. Além da falta de estrutura esbarramos na falta de preparo dos professores para lidar com estas tecnologias, neste sentido que o governo federal por intermédio do Ministério da Educação ${ }^{1}$ está promovendo cursos de especialização e extensão sobre o uso das velhas e novas tecnologias na Educação.

A partir da observação do uso dos computadores e laboratórios por professores de diferentes níveis de ensino (ensino fundamental, médio e superior) observa-se que seus usos são bem diferenciados. Na maioria das vezes os professores levam seus alunos para o laboratório para que utilizem o computador como meio de organizar os trabalhos escolares em torno de um tema que está sendo trabalhado em sala de aula. Poucas são as experiências nas quais os alunos utilizam o computador e os recursos dos laboratórios para pesquisarem e criarem a partir de uma proposta bem elaborada.

Em uma de nossas observações vimos à estratégia de uma professora que torna os próprios alunos do Ensino Fundamental em monitores para auxiliarem os colegas no uso de uma ferramenta de matemática chamada Cabri.

Outra observação interessante foi à construção de paródias através de uma ferramenta chamada cante, a qual permitiu aos alunos transformarem as letras das músicas em poesias, sendo que o trabalho desenvolvido foi sobre Mário Quintana, assim como a construção de vídeos para divulgação do dia de lançamento da Mostra de paródias na escola. O momento de criação foi interessante e prazeroso para os alunos, assim como as produções que ficaram criativas, contextualizadas e bonitas.

Aqui foram mencionadas algumas das experiências de uso das tecnologias de informação e comunicação no meio escolar, embora ainda se tenha muito a caminhar já temos experiências que podem ser compartilhadas e contagiarem outros professores auxiliando-os a planejarem e enriquecerem suas propostas.

\section{Considerações finais}

O acelerado desenvolvimento científico e tecnológico propõe que sejam repensados os meios e as estratégias educacionais, fazendo com que as mesmas respondam, integralmente, às necessidades dos envolvidos nesse processo.

É preciso que seja dado ao professor também espaço e tempo para que ele seja um pesquisador e possa planejar e mudar sua postura frente aos seus alunos. Seu aperfeiçoamento constante através de cursos de formação é essencialmente necessário, assim como espaços de trocas com professores de outras instituições e níveis. Sabemos que este é um processo longo e que muitas são as dificuldades para a mudança na Educação, conforme afirma (MORAN et al., 2000, p.16) "As mudanças demorarão mais do que alguns pensam, porque nos encontramos em processos desiguais de aprendizagens e evolução pessoal e social".

Para que não continuemos repetindo as estratégias e técnicas do passado, precisamos saber que outras possibilidades são possíveis e por isso se faz necessário estar aberto para aprender com os próprios alunos e também com os outros professores, refletindo sempre sobre o que estamos fazendo, para que e como podemos melhorar. Precisamos para isto de educadores maduros intelectual e emocionalmente.

\footnotetext{
${ }^{1}$ Desde setembro de 2006 está sendo promovido pelo Ministério da Educação em parceria com grandes Universidades o curso de extensão - Mídias na Educação - Ciclo básico para professores das redes estadual e municipal de ensino de todos os estados no intuito de trabalhar com as mídias televisão, rádio, impressa e Internet num trabalho que envolve teoria e prática.

V.4 № 2, Dezembro, 2006
} 


\section{Referências}

ALARCÂO, Isabel. Professores reflexivos em uma escola reflexiva. São Paulo: Cortez, 2004.

GANDIN, Danilo. Planejamento como prática educativa. 2. ed. São Paulo: Loyola, 1985.

GANDIN, Luis Armando. Sem planejamento a escola funciona?: Quem está planejando a escola?. In: Revista de educação AEC. Brasília Vol. 33, n. 132 (jul./set. 2004).

MANATA, Dora Vianna. Planejamento docente, questão didática: "tenho tudo planejado na cabeça". In: Revista de educação AEC. Brasília, DF Vol. 33, n. 132 (jul./set. 2004).

MENEZES, Ebenezer Takuno de; SANTOS, Thais Helena dos."Mediação pedagógica" (verbete). Dicionário Interativo da Educação Brasileira - EducaBrasil. São Paulo: Midiamix Editora. Disponível em: < http://www.educabrasil.com.br/eb/dic/dicionario.asp?id=44>, Acesso em 15/11/2006.

MORAN, José Manuel; MASETTO, Marcos T.; BEHRENS, Marilda Aparecida. Novas Tecnologias e mediação pedagógica. São Paulo: Papirus, 2000.

PEREZ, Francisco Gutiérrez; CASTILLO, Daniel Prieto. La mediación pedagógica. Buenos Aires: Ciccus, 1999.

RODRIGUES, Maria Bernadette Castro. Planejamento: desamarrando nós, atando o fazer pedagógico. In: Reconstrução curricular na escola democrática e popular: desafio para rede pública estadual no município de Porto Alegre. Porto Alegre: UFRGS. Núcleo de Integração Universidade \& Escola; Secretaria Estadual de Educação. Departamento de Coordenação das Regionais, 2002.

TARDIF, Maurice; LESSARD, Claude. O trabalho docente: Elementos para uma teoria da docência como profissão de interações humanas. Rio de Janeiro: Vozes, 2005. 